\title{
Mepolizumab reduces exacerbations in patients with severe eosinophilic asthma, irrespective of body weight/body mass index: meta-analysis of MENSA and MUSCA
}

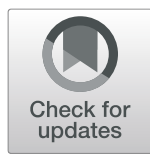

Frank C. Albers ${ }^{1,7^{*}}$ (D, Alberto Papi ${ }^{2}$, Camille Taillé ${ }^{3}$, Daniel J. Bratton ${ }^{4}$, Eric S. Bradford ${ }^{5}$, Steven W. Yancey ${ }^{5}$ and Namhee Kwon ${ }^{6}$

\begin{abstract}
Background: We assessed the efficacy of the licensed mepolizumab dose (100 mg subcutaneously [SC]) in patients with severe eosinophilic asthma according to body weight/body mass index (BMI).

Methods: This was a post hoc individual patient-level meta-analysis of data from the Phase 3 studies MENSA (MEA115588/NCT01691521) and MUSCA (200862/NCT02281318). Patients aged $\geq 12$ years with severe eosinophilic asthma and a history of exacerbations were randomised to 4-weekly placebo, mepolizumab $75 \mathrm{mg}$ intravenously (IV) or 100 mg SC (MENSA) or placebo or mepolizumab 100 mg SC (MUSCA) for 32 (MENSA) or 24 (MUSCA) weeks. The primary endpoint was the annual rate of clinically significant exacerbations; other outcomes included the proportion of patients with no exacerbations, lung function, St George's Respiratory Questionnaire (SGRQ) and Asthma Control Questionnaire-5 (ACQ-5) scores and blood eosinophil counts. Analyses were performed by baseline body weight and BMI ( $\leq 60,>60-75,>75-90,>90,<100, \geq 100 \mathrm{~kg}$; $\left.\leq 25,>25-30,>30,<36, \geq 36 \mathrm{~kg} / \mathrm{m}^{2}\right)$.

Results: Overall, 936 patients received placebo or mepolizumab $100 \mathrm{mg} \mathrm{SC}$. Across all body weight/BMl categories, mepolizumab reduced the rate of clinically significant exacerbations by $49-70 \%$ versus placebo. Improvements with mepolizumab versus placebo were also seen in lung function in all body weight/BMl categories except $>90 \mathrm{~kg}$; improvements in SGRQ and ACQ-5 scores were seen across all categories.
\end{abstract}

Conclusions: Mepolizumab 100 mg SC has consistent clinical benefits in patients with severe eosinophilic asthma across a range of body weights and BMIs. Data show that the fixed-dose regimen of mepolizumab is suitable, without the need for weight-based dosing.

Trial registration: This manuscript is a post hoc meta-analysis of data from the Phase 3 studies MENSA and MUSCA. ClinicalTrials.gov, NCT01691521 (MEA115588; MENSA). Registered September 24, 2012. ClinicalTrials.gov, NCT02281318 (200862; MUSCA). Registered November 3, 2014.

Keywords: Asthma, Asthma pharmacology, Body mass index, Body weight, Mepolizumab

\footnotetext{
* Correspondence: frank-c.albers@t-online.de

${ }^{1}$ Respiratory Medical Franchise, GSK, Research Triangle Park, NC, USA

PPresent address: Avillion US Inc., Northbrook, IL, USA

Full list of author information is available at the end of the article
}

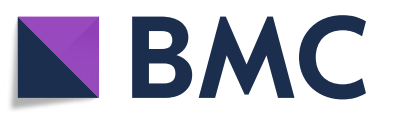

(c) The Author(s). 2019 Open Access This article is distributed under the terms of the Creative Commons Attribution 4.0 International License (http://creativecommons.org/licenses/by/4.0/), which permits unrestricted use, distribution, and reproduction in any medium, provided you give appropriate credit to the original author(s) and the source, provide a link to the Creative Commons license, and indicate if changes were made. The Creative Commons Public Domain Dedication waiver (http://creativecommons.org/publicdomain/zero/1.0/) applies to the data made available in this article, unless otherwise stated. 


\section{Background}

Asthma affects an estimated 339 million people worldwide [1], with $5-10 \%$ of this population having severe asthma, characterised by frequent, persistent respiratory symptoms, despite the regular use of maintenance therapies and additional controllers [2]. Severe asthma is a heterogeneous condition, with a number of clinical phenotypic expressions including severe eosinophilic asthma $[2,3]$. Patients with severe eosinophilic asthma often develop disease in adult life, experience recurrent exacerbations and characteristically show eosinophilic inflammation despite appropriate treatment $[2,3]$, highlighting a need for more targeted therapy.

Mepolizumab is a monoclonal antibody (mAb) that selectively targets interleukin (IL)-5 and inhibits eosinophilic inflammation $[4,5]$. In Phase 3 clinical studies, mepolizumab treatment was associated with reduced rates of exacerbations, decreased oral glucocorticoid dependence and improved lung function, asthma control and health-related quality of life (HRQoL), compared with placebo [6-8]. Mepolizumab is approved in the US and Europe for use as an add-on treatment for patients with severe eosinophilic asthma, and the licensed dose for adults and adolescents, administered subcutaneously (SC), is fixed at $100 \mathrm{mg}$, regardless of body weight $[4,5]$. A fixed-dose regimen is preferred since it reduces the likelihood of dosing errors and drug wastage compared with a treatment regimen in which the dose is determined according to body weight [9]. However, overweight and obese patients may display reduced responses to some treatments as a result of altered drug bioavailability [10, 11]. As such, it is important to explore the treatment response of fixed-dosed regimens across a wide spectrum of body compositions.

The aim of this post hoc meta-analysis of data from two Phase 3 clinical trials, MENSA (MEA115588/NCT01691521) and MUSCA (200862/NCT02281318) [7, 8], was to assess the efficacy of the licensed dose of mepolizumab (100 mg SC) versus placebo in patients with severe eosinophilic asthma according to body weight and body mass index (BMI).

\section{Methods}

\section{Study design}

This was a post hoc individual patient-level meta-analysis of data from two Phase 3, placebo-controlled, randomised, double-blind, parallel-group, multicentre studies, MENSA and MUSCA [7, 8], which assessed the licensed dose of mepolizumab (100 mg SC) in patients with severe eosinophilic asthma. Results of these studies have been reported previously [7, 8]. In brief, patients enrolled in MENSA were randomised $(1: 1: 1)$ to receive mepolizumab $75 \mathrm{mg}$ intravenously (IV), mepolizumab $100 \mathrm{mg}$ SC or placebo, plus standard of care (high-dose inhaled corticosteroids [ICS] and another controller), every 4 weeks for 32 weeks. Patients enrolled in MUSCA were randomised (1:1) to receive mepolizumab $100 \mathrm{mg}$ SC or placebo, plus standard of care, every 4 weeks for 24 weeks. This post hoc analysis reports data from patients who received placebo or mepolizumab $100 \mathrm{mg}$ SC only. MENSA and MUSCA were conducted in accordance with the ethical principles of the Declaration of Helsinki, International Conference on Harmonisation Good Clinical Practice Guidelines, and applicable country-specific regulatory requirements.

\section{Patients}

MENSA and MUSCA enrolled patients aged $\geq 12$ years with severe eosinophilic asthma (blood eosinophil count: $\geq 300$ cells $/ \mu \mathrm{L}$ in the previous year; or $\geq 150$ cells $/ \mu \mathrm{L}$ at screening) who had a history of $\geq 2$ exacerbations (requiring systemic corticosteroids) in the 12 months prior to screening despite regular treatment with high-dose ICS during the same period, plus additional controller medication(s) with or without oral corticosteroids (OCS) for $\geq 3$ months. Neither study included specific body weight or BMI inclusion criteria. Data from patients who received $\geq 1$ dose of either placebo or mepolizumab were included in this meta-analysis; this was the modified intent-to-treat population.

\section{Endpoints and assessments}

The primary endpoint was the annual rate of clinically significant exacerbations (defined as a worsening of asthma that required the use of systemic corticosteroids and/or hospitalisation/emergency department visit). Secondary endpoints included the proportion of patients with no clinically significant exacerbations over the course of the study, change from baseline in pre-bronchodilator forced expiratory volume in 1 $\mathrm{s}\left(\mathrm{FEV}_{1}\right)$ at study end, change from baseline in St George's Respiratory Questionnaire (SGRQ) total score at study end, the proportion of responders achieving a $\geq 4$-point reduction (minimal clinically important difference [MCID] [12]) from baseline in SGRQ total score at study end, change from baseline in Asthma Control Questionnaire (ACQ-5) score at study end, the proportion of responders achieving $\mathrm{a} \geq 0.5$ point reduction (MCID [13]) from baseline in ACQ-5 score at study end, and the change from baseline in blood eosinophil count at study end.

\section{Sample size and statistical analysis}

Analyses were stratified by body weight (categories: $\leq 60$, $>60-75,>75-90$ and $>90 \mathrm{~kg}$ [all endpoints]; thresholds: $<100$ and $\geq 100 \mathrm{~kg}$ [primary endpoint only]) and BMI (categories: $\leq 25,>25-30$ and $>30 \mathrm{~kg} / \mathrm{m}^{2}$ [all endpoints]; thresholds: $<36$ and $\geq 36 \mathrm{~kg} / \mathrm{m}^{2}$ [primary endpoint only]). Body weight categories were selected based on cut-offs used in analyses of previous mepolizumab studies. BMI categories were selected based on those generally used in clinical practice to define normal weight, overweight and obese. 
The rate of exacerbations was analysed separately for each subgroup in each study using a negative binomial model, including the log of time on treatment as an offset variable. Continuous endpoints, including changes from baseline in pre-bronchodilator $\mathrm{FEV}_{1}$, SGRQ total score (scale 0-100, with higher scores indicating worse HRQoL), ACQ-5 score, and blood eosinophil count, were analysed using a mixed model repeated measures analysis. The proportion of patients with no clinically significant exacerbations and the proportions of SGRQ total score and ACQ-5 score responders were analysed using a logistic regression model. All model-based analyses were adjusted for treatment, number of exacerbations in the previous year $(2,3, \geq 4)$, baseline maintenance OCS use, baseline pre-bronchodilator percent predicted $\mathrm{FEV}_{1}$ (except analysis of $\mathrm{FEV}_{1}$ ), geographical region, and baseline value of the analysis variable (where applicable). End-of-study treatment differences between mepolizumab $100 \mathrm{mg} \mathrm{SC}$ and placebo for each subgroup were combined across studies using an inverse variance weighted fixed-effects metaanalysis. The protocol for the meta-analysis is available on the GSK Clinical Studies Register (Study ID 208115) [14].

\section{Results}

\section{Patient population}

In total, 1136 patients who participated in the MENSA and MUSCA studies received $\geq 1$ dose of study treatment and were included in the analysis. Of these, 936 were randomised to receive either placebo $(n=468)$ or mepolizumab $100 \mathrm{mg} \mathrm{SC}(n=468)$. Patient demographics and baseline characteristics by body weight and BMI categories and thresholds are shown in Table 1 . At baseline, patients had a mean weight of $78.1 \mathrm{~kg}$ and BMI of $28.0 \mathrm{~kg} / \mathrm{m}^{2}$. In general, mean age was similar across body weight and BMI subgroups. Patients in the higher BMI and weight categories generally had worse SGRQ scores compared with those in the lower categories. Across subgroups, around onequarter of patients were receiving OCS maintenance therapy at baseline.

\section{Primary endpoint}

Across all body weight categories and thresholds, mepolizumab $100 \mathrm{mg}$ SC treatment was associated with reductions of $50-70 \%$ in the annual rate of clinically significant exacerbations compared with placebo (Fig. 1). Reductions of $49-62 \%$ in the annual rate of clinically significant exacerbations were also seen across BMI categories and thresholds with mepolizumab versus placebo (Fig. 2).

\section{Secondary endpoints}

Regardless of body weight category, patients receiving mepolizumab $100 \mathrm{mg}$ SC were more likely to experience no clinically significant exacerbations during the study period than those who received placebo, with odds ratios to placebo ranging between 2.99 (95\% confidence interval $[\mathrm{CI}]: 1.64,5.44)$ in the $>75-90 \mathrm{~kg}$ subgroup and 5.18 (95\% CI: 2.17, 12.33) in the lowest weight subgroup of $\leq 60 \mathrm{~kg}$ (Fig. 3). Similar results were seen across BMI categories, with odds ratios to placebo ranging from 2.96 (95\% CI: 1.70, 5.16) in patients in the highest BMI subgroup of BMI $>30 \mathrm{~kg} / \mathrm{m}^{2}$ to 3.53 (95\% CI: 2.07, 6.03) in those with a BMI $>25-30 \mathrm{~kg} / \mathrm{m}^{2}$.

Mepolizumab treatment resulted in an increase from baseline in pre-bronchodilator $\mathrm{FEV}_{1}$ versus placebo in patients with body weight $\leq 60,>60-75$ and $>75-90 \mathrm{~kg}$ (treatment difference ranged from 98 to $172 \mathrm{~mL}$ ), but not in patients with body weight $>90 \mathrm{~kg}$ (treatment difference: $-14 \mathrm{~mL}$ ) (Fig. 4). Across all BMI categories, mepolizumab treatment resulted in an increase from baseline in pre-bronchodilator $\mathrm{FEV}_{1}$ versus placebo, with a smaller effect in the highest BMI category (treatment difference ranged from 43 to $158 \mathrm{~mL}$ ) (Fig. 4).

Improvements from baseline with mepolizumab versus placebo were observed in SGRQ total score at study end, irrespective of body weight or BMI category. Treatment differences ranged from -5.5 to -9.7 points across weight categories, and from -5.7 to -9.3 points across BMI categories (Fig. 5a). In addition, patients receiving mepolizumab treatment were more likely to achieve a clinically meaningful response of $\geq 4$-point reduction (MCID) from baseline in SGRQ total score compared with patients receiving placebo, irrespective of body weight or BMI category (Fig. 5b).

Mepolizumab was associated with improvements from baseline in ACQ-5 score at study end, compared with placebo, across all body weight categories (treatment difference ranged from -0.32 to -0.48 points) and all BMI categories (treatment difference ranged from -0.28 to 0.51) (Fig. 6a). Patients in all body weight categories were also more likely to achieve a clinically meaningful improvement of $\geq 0.5$-point reduction from baseline in ACQ-5 score (MCID) when treated with mepolizumab versus placebo (odds ratio ranged from 1.21 to 2.31), as were patients across all BMI categories (odds ratio ranged from 1.55 to 2.19) (Fig. 6b).

Reductions from baseline in blood eosinophil count were seen in mepolizumab- versus placebo-treated patients across all body weight categories, with reductions ranging from $83 \%$ (ratio [95\% CI]: $0.17[0.13,0.21]$ ) in the $>75-90 \mathrm{~kg}$ subgroup to $74 \%(0.26[0.20,0.33])$ in the $>90 \mathrm{~kg}$ subgroup (Fig. 7). Across BMI categories, mepolizumab treatment resulted in greater reductions from baseline in blood eosinophil count than placebo treatment, ranging from $83 \%(0.17[0.14,0.21])$ in the $\leq 25 \mathrm{~kg} / \mathrm{m}^{2}$ subgroup to $76 \%(0.24[0.19,0.30])$ in the $>30 \mathrm{~kg} / \mathrm{m}^{2}$ subgroup (Fig. 7). 


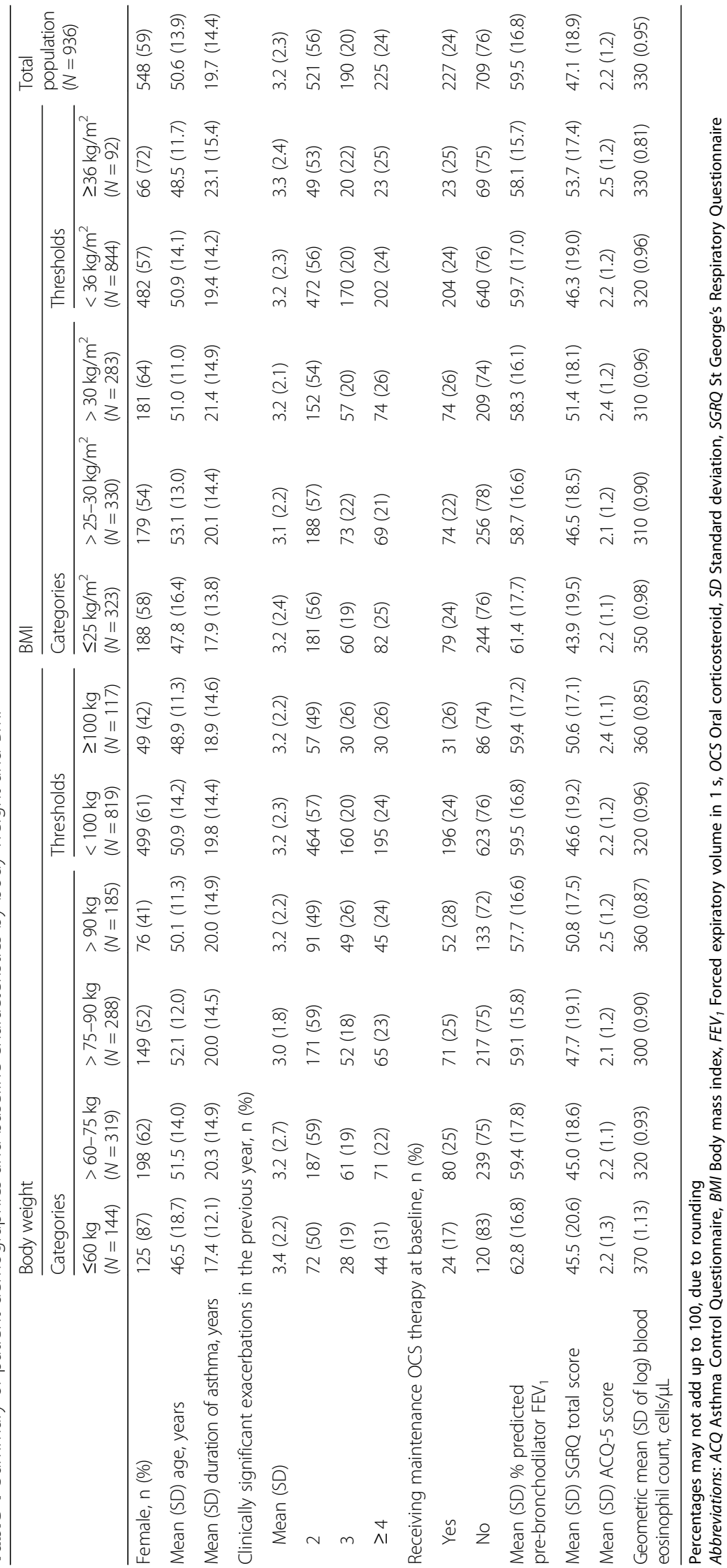




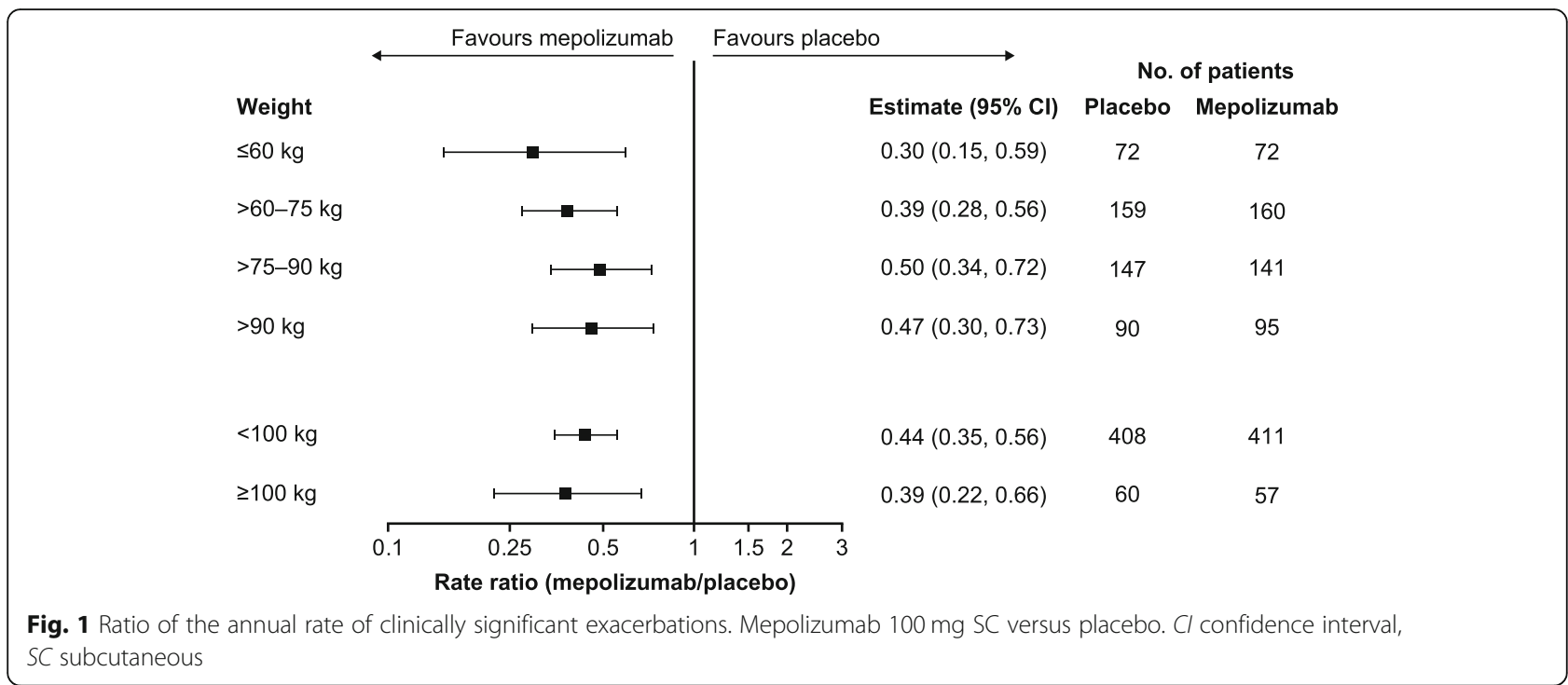

\section{Discussion}

In this post hoc meta-analysis of the MENSA and MUSCA studies, the licensed dose of mepolizumab (100 mg SC) showed consistent improvements versus placebo in exacerbation rate, HRQoL and asthma control, independent of patients' body weight or BMI. These data demonstrate comparable efficacy of mepolizumab in patients with either high or low body weight/BMI, and confirm that dose-weight adjustments with mepolizumab are not required, thereby addressing queries regarding the need for higher mepolizumab doses in patients with high body weight/BMI. Our findings reinforce the suitability of a simple, fixed-dose regimen across all ranges of body weight/BMI in eligible patients.

Several novel biologic treatments approved for use in patients with differing severe asthma phenotypes have demonstrated reduced efficacy in patients who are obese. For example, a recent retrospective study in patients with severe asthma $(N=340)$ found that obesity may reduce the effectiveness of the anti-immunoglobulin $\mathrm{E} \mathrm{mAb}$ omalizumab, independent of other asthmainfluencing factors [15]. In addition, a post hoc pooled analysis of the Phase 3 SIROCCO and CALIMA trials demonstrated that the effects of the anti-IL- 5 receptor $\mathrm{mAb}$ benralizumab on the annual rate of exacerbations and lung function in patients with severe eosinophilic asthma were less robust in obese individuals than in those who were of normal weight [16]. It is important to note that the DREAM study, which was a double-blind, placebo-controlled trial assessing mepolizumab in patients with severe eosinophilic asthma, showed no dosing effect over a 10-fold dose range of mepolizumab on exacerbation rate and other outcomes [17]. For this reason it was important to further investigate whether there was any relationship between

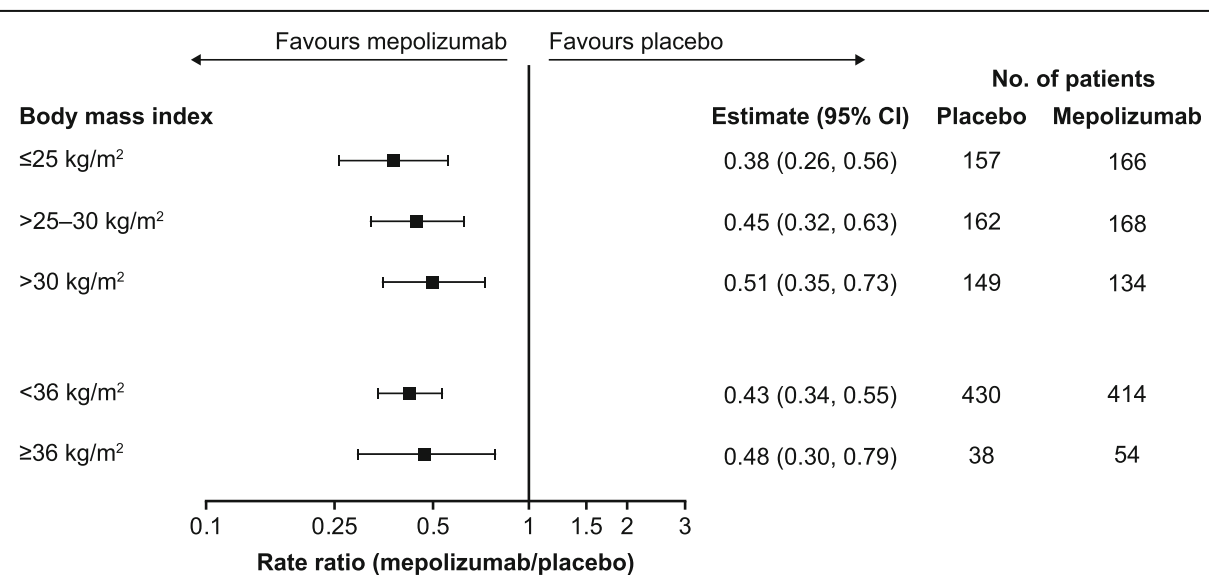

Fig. 2 Ratio of the annual rate of clinically significant exacerbations. Mepolizumab $100 \mathrm{mg}$ SC versus placebo. BMI body mass index, Cl confidence interval, SC subcutaneous 


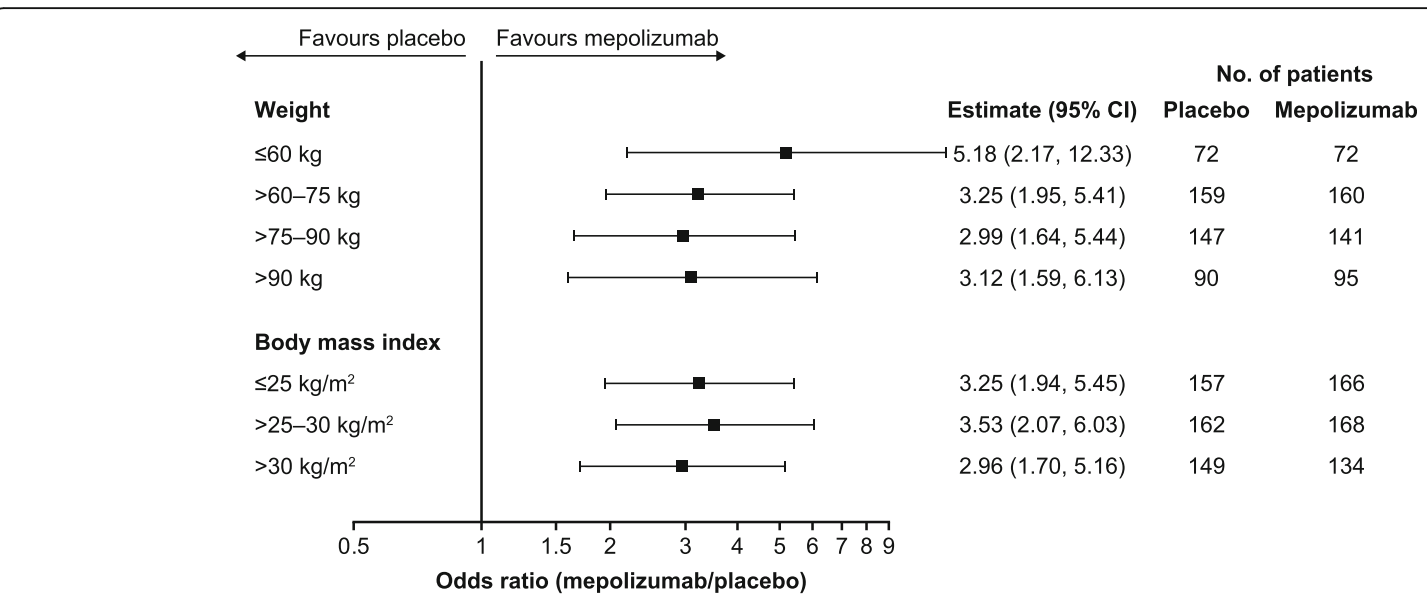

Fig. 3 Proportion of patients experiencing no clinically significant exacerbation. Mepolizumab $100 \mathrm{mg}$ SC versus placebo. BMI body mass index, Cl confidence interval, SC subcutaneous

mepolizumab efficacy and body weight/BMI in patients with severe eosinophilic asthma.

To date, the effect of mepolizumab $100 \mathrm{mg}$ SC in patients with high body weight/BMI has not been extensively investigated. However, a post hoc analysis of the DREAM study suggested that mepolizumab remains efficacious in these individuals $[18,19]$. In this analysis responder subgroups were identified using cluster analysis; the cluster demonstrating greatest response to mepolizumab was an obese, eosinophilic group with airway reversibility [19]. Moreover, a post hoc analysis of the MENSA and DREAM studies showed that treatment with mepolizumab (doses of 75,250 or $750 \mathrm{mg}$ IV or $100 \mathrm{mg} \mathrm{SC}$ ) resulted in similar exacerbation rate reductions across weight categories of $\leq 60 \mathrm{~kg},>60-\leq 75 \mathrm{~kg},>75-\leq 90 \mathrm{~kg}$ and $>90 \mathrm{~kg}$, with no discernible trend noted in exacerbation reductions with the $250 \mathrm{mg}$ and $750 \mathrm{mg}$ IV doses of mepolizumab, even at the higher weight categories (Additional file 1: Table S1)
[20]. In the current analysis, mepolizumab treatment was associated with reduced exacerbation rates across all body weight and BMI categories, versus placebo. In addition, mepolizumab induced an increase from baseline in prebronchodilator $\mathrm{FEV}_{1}$ versus placebo in all body weight categories except $>90 \mathrm{~kg}$. A similar trend was observed in the BMI categories. This is consistent with results from post hoc analyses of data from Phase 3 trials of benralizumab $[16,21]$. For example, it has been shown that the increase in pre-bronchodilator $\mathrm{FEV}_{1}$ following benralizumab treatment was lower in patients with extremely high body weight $(\geq 115 \mathrm{~kg})$ compared with those with a body weight $<115 \mathrm{~kg}$ [21]. It is possible that mechanical factors causing airway restriction may be responsible for a reduced treatment response in obese patients [15], although it should also be noted that low patient numbers in the highest body weight category may have contributed to this observation in our analysis.

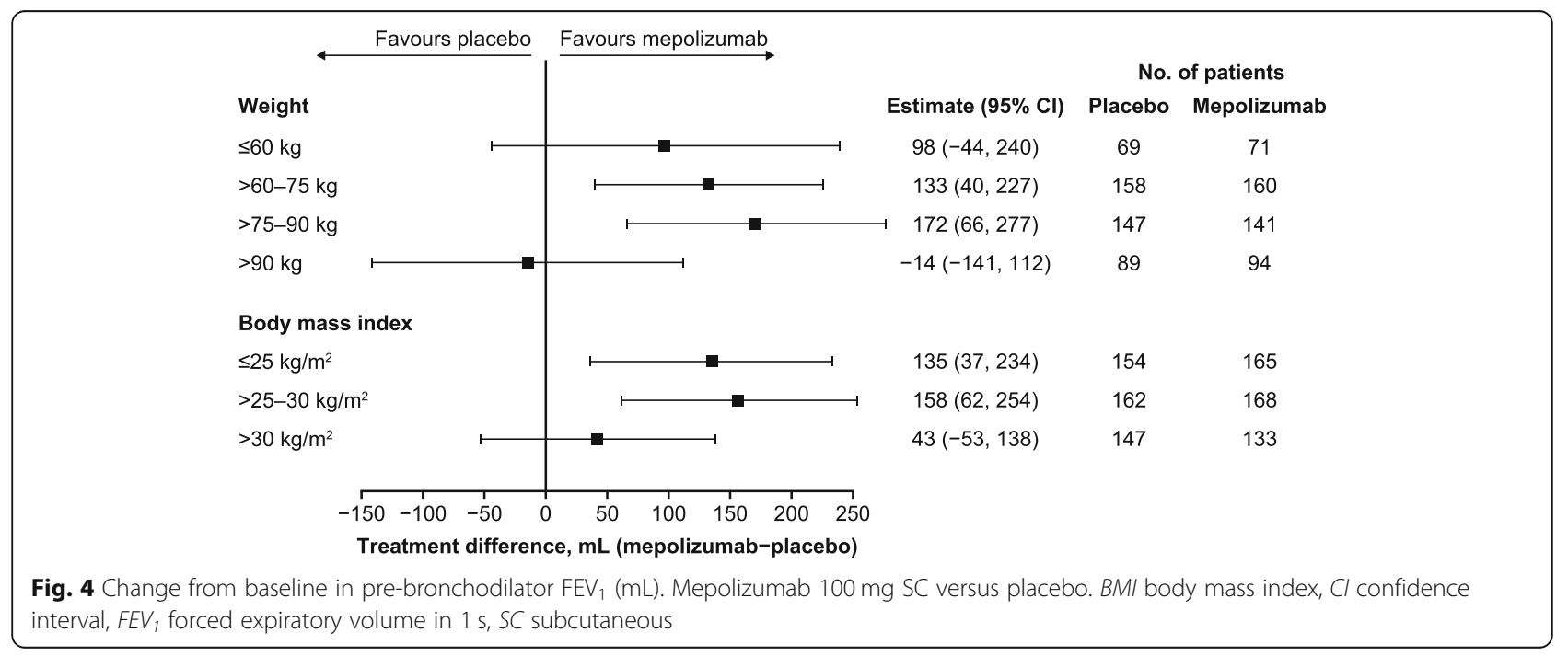



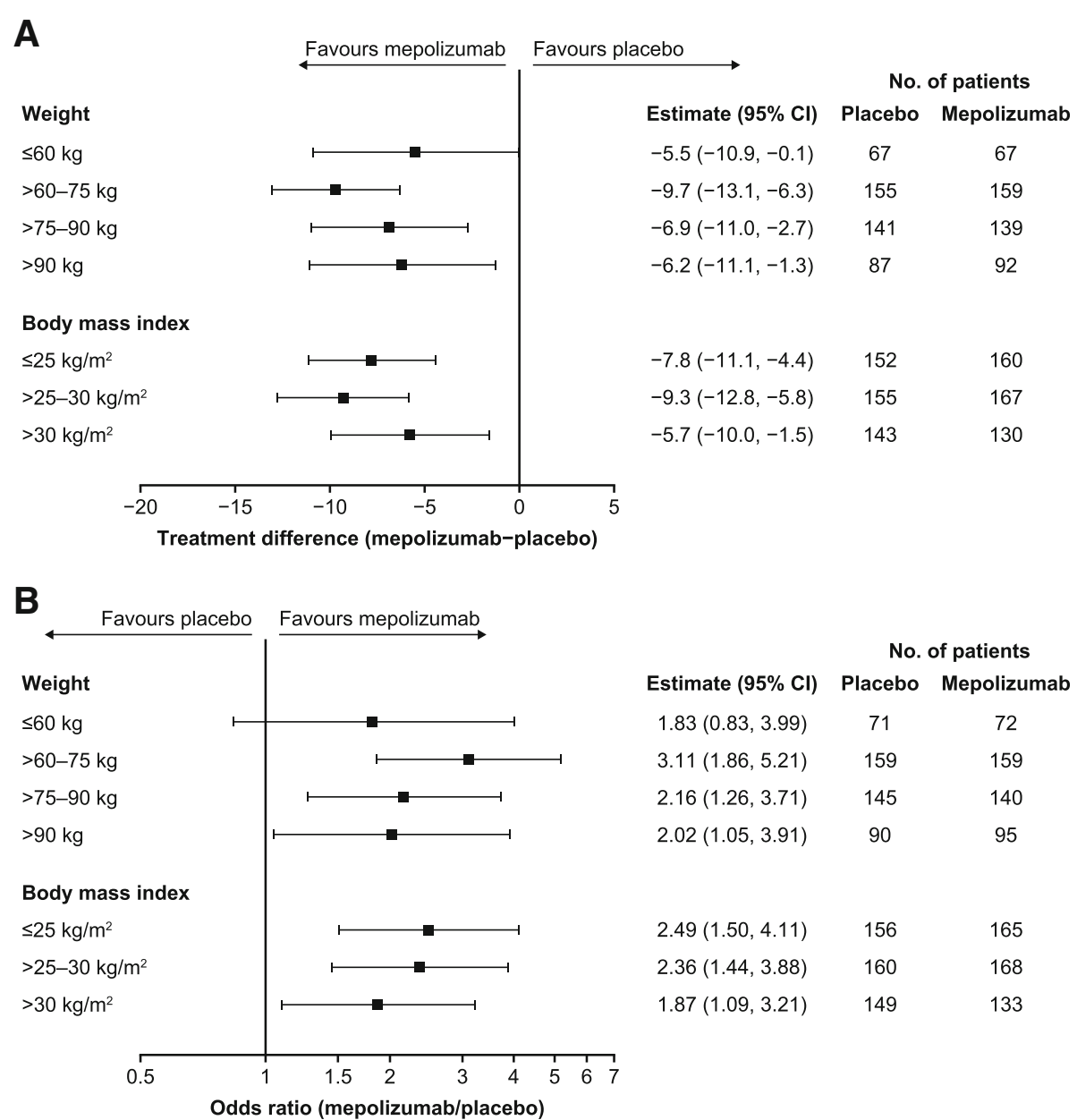

\begin{tabular}{ccc} 
& \multicolumn{2}{c}{ No. of patients } \\
Estimate $(95 \%$ CI) & Placebo & Mepolizumab \\
$1.83(0.83,3.99)$ & 71 & 72 \\
$3.11(1.86,5.21)$ & 159 & 159 \\
$2.16(1.26,3.71)$ & 145 & 140 \\
$2.02(1.05,3.91)$ & 90 & 95 \\
& & \\
$2.49(1.50,4.11)$ & 156 & 165 \\
$2.36(1.44,3.88)$ & 160 & 168 \\
$1.87(1.09,3.21)$ & 149 & 133
\end{tabular}

Fig. 5 Change from baseline in SGRQ total score (a) and proportion of responders achieving a $\geq 4$-point change from baseline in SGRQ total score (b). Mepolizumab $100 \mathrm{mg}$ SC versus placebo. BMI body mass index, Cl confidence interval, SC subcutaneous, SGRQ St George's Respiratory Questionnaire

Consistent improvements in both SGRQ total score and ACQ-5 score were also seen with mepolizumab versus placebo across all body weight and BMI categories, including patients with body weight $>90 \mathrm{~kg}$. Although the effects of mepolizumab on measures of HRQoL and asthma control have been reported several times previously in populations with severe eosinophilic asthma [7, 8], this is the first analysis to demonstrate a consistent effect on these parameters across all body weight and BMI categories. Given the particularly poor QoL and reduced asthma control in patients with asthma and comorbid obesity [22], this is a clinically important finding.

Also of clinical relevance is the consistent and sustained reduction in blood eosinophil count with mepolizumab versus placebo shown in this study, regardless of body weight/ BMI. This finding builds upon a substantial body of evidence demonstrating mepolizumab-induced reductions in blood eosinophil levels and a correlation between reduced blood eosinophils and improvements in clinical parameters such as exacerbations and lung function [7, 8]. Of particular importance in this analysis, obesity was previously thought to be associated with a non-eosinophilic asthma phenotype that is typically unresponsive to steroids and therefore not considered to be eligible for treatment with mepolizumab [18]. However, more recently, elevated sputum IL-5 and submucosal and sputum eosinophils have been reported in obese patients with asthma [18, 23, 24]. The baseline patient characteristics in the current study are in line with this finding, with no obvious trend for lower blood eosinophil counts in patients with higher body weight or BMI, albeit in a population of patients who satisfied inclusion criteria pertaining to eosinophilic asthma. Together, these data suggest that patients with high body weight/BMI can have raised blood eosinophil levels and therefore be eligible for mepolizumab treatment, and further, that mepolizumab $100 \mathrm{mg}$ SC can be efficacious in this population. One important consideration is the evidence that inflammatory biomarkers, including blood eosinophils, may be less predictive of airway 


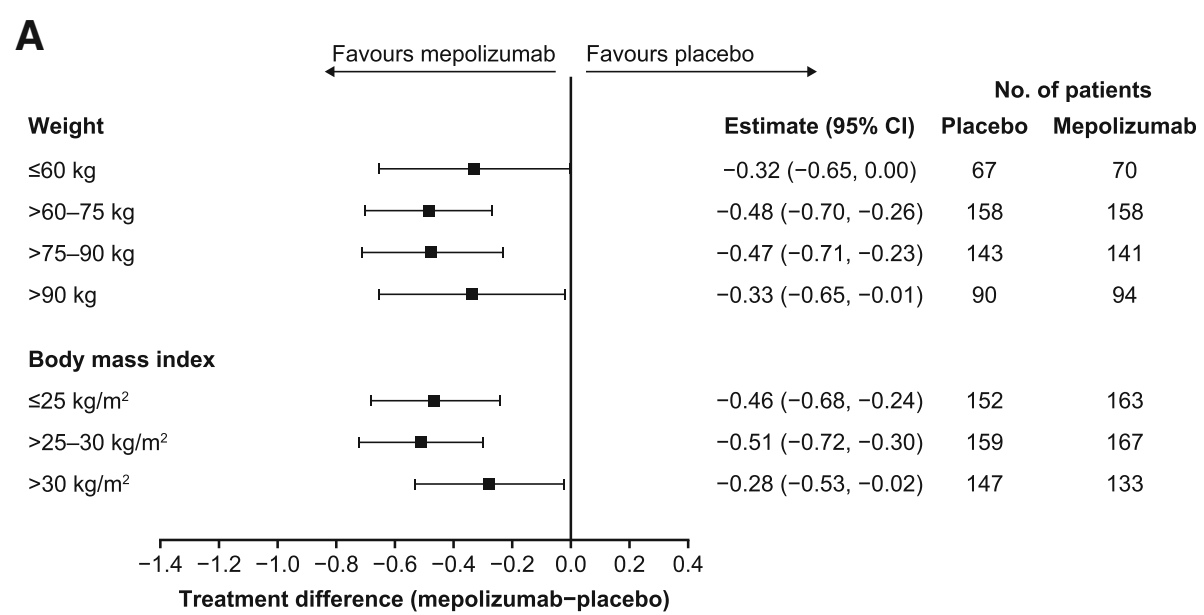

B

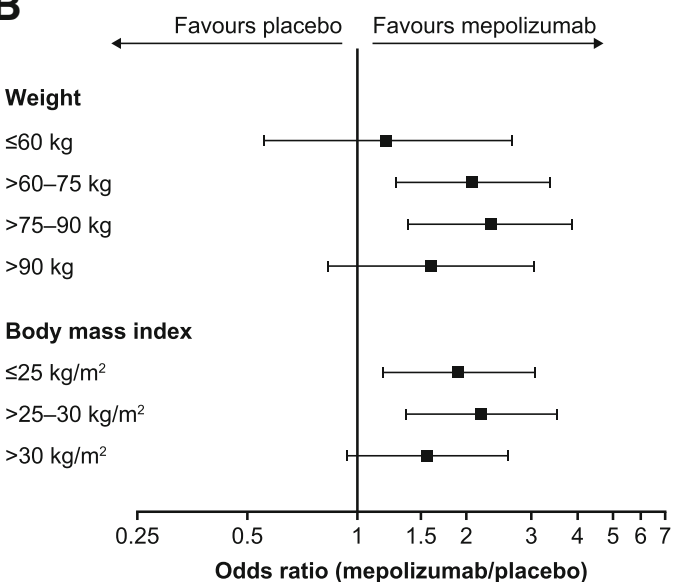

No. of patients Estimate $(95 \% \mathrm{Cl})$ Placebo Mepolizumab $1.21(0.55,2.65) \quad 70 \quad 71$ $2.08(1.28,3.38) \quad 159 \quad 158$ $2.31(1.38,3.88) \quad 143 \quad 141$ $1.60(0.83,3.07) \quad 90 \quad 95$

$1.90(1.17,3.07) \quad 155 \quad 164$ $2.19(1.36,3.53) \quad 159 \quad 167$ $1.55(0.94,2.57) \quad 148 \quad 134$

Fig. 6 Change from baseline in ACQ-5 score (a) and proportion of responders achieving a $\geq 0.5$-point change from baseline in ACQ-5 score (b). Mepolizumab 100 mg SC versus placebo. ACQ-5 Asthma Control Questionnaire, BMI body mass index, Cl confidence interval, SC subcutaneous

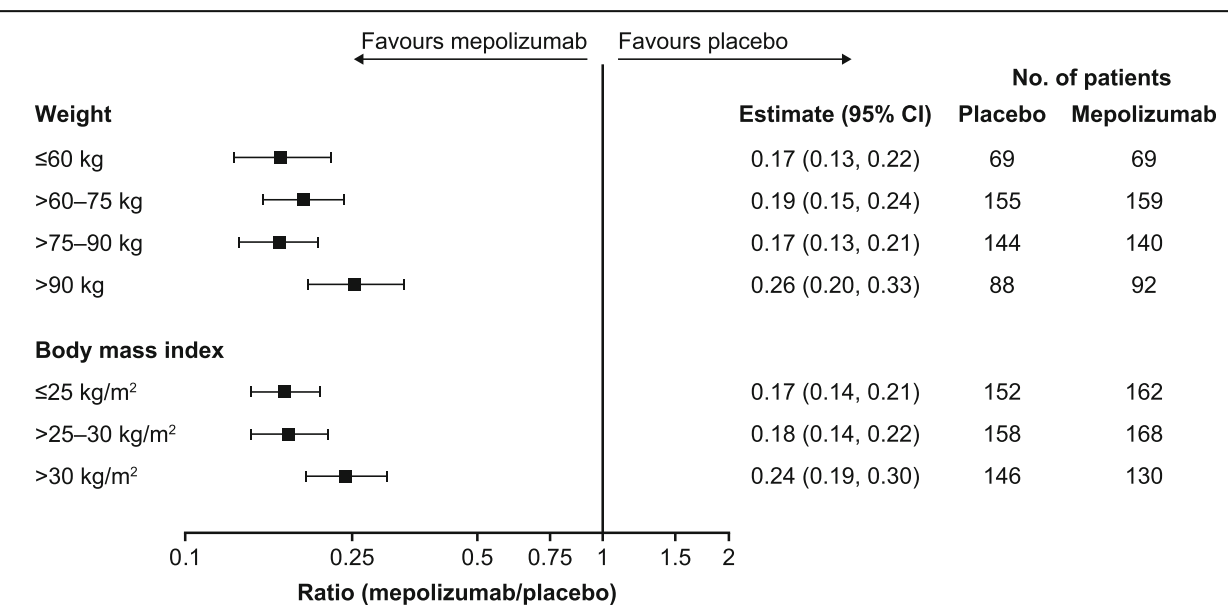

Fig. 7 Ratio to baseline in blood eosinophil count. Mepolizumab 100 mg SC versus placebo. BMI body mass index, Cl confidence interval, SC subcutaneous 
eosinophilia in obese patients [25]. Nonetheless, the current analysis has demonstrated improvements in a range of clinical parameters in a population of patients with severe eosinophilic asthma across body weight and BMI categories.

Body weight typically influences the exposure of biologics [26]. However, whether this exposure difference translates into a meaningful efficacy difference also depends on the drug-to-target ratio. For omalizumab to adequately neutralise immunoglobulin $\mathrm{E}$ levels, a weightbased dosing strategy was deemed necessary [27]. By contrast, neutralisation of IL-5 levels with a fixed-dose regimen of mepolizumab $100 \mathrm{mg} \mathrm{SC}$ was found to be efficacious and sufficient over the expected body weight/ BMI range in adults and adolescents. A previously reported analysis showed that the efficacy dose-response was consistent with that of the well-defined pharmacological dose-response, in which the half-maximal effect was estimated at $11 \mathrm{mg} \mathrm{SC}$ [28], which is well below the licensed dose of $100 \mathrm{mg} \mathrm{SC}$. Unlike mepolizumab, the clinical development programme for reslizumab only investigated a $\mathrm{mg} / \mathrm{kg}$ dosing regimen and reslizumab is therefore dosed according to body weight [29].

Combining data from two large randomised, controlled trials in the current analysis provided a large sample in which to determine the effect of mepolizumab across a range of body compositions. However, there are several limitations that should be considered. First, the post hoc nature of the analysis should be considered when interpreting the findings. In addition, the number of patients varied substantially between subgroups, with smaller patient numbers in the highest body weight and BMI subgroups. We also did not investigate whether there were any differences in safety findings between the subgroups, although previous studies have demonstrated that mepolizumab is well tolerated with minimal immunogenic potential [6-8]. Despite these limitations, our findings provide valuable insights into the use of mepolizumab in patients with severe eosinophilic asthma.

\section{Conclusions}

In summary, results from this post hoc analysis of the MENSA and MUSCA studies demonstrate that mepolizumab $100 \mathrm{mg}$ SC is associated with improvements in exacerbation rate, HRQoL and asthma control in patients with severe eosinophilic asthma, across a range of patient body weights and BMI categories. The reason for a lower improvement in $\mathrm{FEV}_{1}$ in the highest body weight category remains to be investigated. Nonetheless, our findings support the use of a simple, fixed-dose regimen of mepolizumab $100 \mathrm{mg}$ SC for treating patients with severe eosinophilic asthma.

\section{Additional file}

Additional file 1: Table S1. Rate ratio of clinically significant exacerbations by body weight in the MENSA and DREAM studies (intentto-treat population). (PDF $590 \mathrm{~kb}$ )

\section{Abbreviations}

ACQ-5: Asthma Control Questionnaire-5; BMI: Body mass index; FEV ${ }_{1}$ : Forced expiratory volume in $1 \mathrm{~s}$; HRQoL: Health-related quality of life; ICS: Inhaled corticosteroids; IL: Interleukin; IV: Intravenously; mAb: monoclonal antibody; OCS: Oral corticosteroids; SC: Subcutaneously; SGRQ: St George's Respiratory Questionnaire

\section{Acknowledgements}

This post hoc meta-analysis (GSK ID: 208115) and the parent studies (MENSA, MEA115588/NCT01691521; MUSCA, 200862/NCT02281318) were funded by GlaxoSmithKline (GSK). Editorial support (in the form of writing assistance, including development of the initial draft from the study report, assembling tables and figures, collating author comments, grammatical editing and referencing) was provided by Laura Pearce, PhD, and Roisin McCorkell, MSc, of Fishawack Indicia Ltd., UK, and was funded by GSK.

\section{Authors' contributions}

DJB and FCA contributed to the conception and design of the analysis. CT was involved in the acquisition of the data during the primary studies. All authors contributed to the analysis and interpretation of the data, development of the manuscript and approval of the final draft to be published.

\section{Funding}

This post hoc meta-analysis (GSK ID: 208115) and the parent studies (MENSA, MEA115588/NCT01691521; MUSCA, 200862/NCT02281318) were funded by GSK. Editorial support (in the form of writing assistance, including development of the initial draft based on author direction, assembling tables and figures, collating authors' comments, grammatical editing and referencing) was funded by GSK. All authors had roles in the conception, design and interpretation of the analysis. All authors participated in the development of the manuscript and had access to the data from the studies. The decision to submit for publication was that of the authors alone. The sponsor did not place any restrictions on access to the data or on the statements made in the manuscript. The corresponding author had final responsibility for the decision to submit for publication.

\section{Availability of data and materials}

Anonymised individual participant data from the studies listed within this publication and their associated documents can be requested for further research from www.clinicalstudydatarequest.com.

\section{Ethics approval and consent to participate}

All patients provided written informed consent for MENSA and MUSCA. The original MENSA and MUSCA study protocols (on which this analysis was based) were approved by local or national research ethics committees. Both MENSA and MUSCA were conducted in accordance with the ethical principles of the Declaration of Helsinki, the International Conference on Harmonisation Good Clinical Practice guidelines, and the applicable countryspecific regulatory requirements.

\section{Consent for publication}

Not applicable.

\section{Competing interests}

DJB, ESB, SWY and NK are employees of GSK and hold stocks/shares in GSK. FCA was an employee of GSK at the time of this analysis and holds stocks/ shares in GSK. AP has received grants, personal fees and non-financial support and other from AstraZeneca, Teva, Mundipharma, GSK, Chiesi and Boehringer Ingelheim; has received personal fees and non-financial support from Novartis, Menarini and Zambon; and has received grants from Sanofi. CT has received fees from GSK, AstraZeneca, Novartis, Teva, Sanofi, Genzyme and Roche (consultancy, advisory boards) and was an investigator in trials involving GSK, AstraZeneca, Novartis, Sanofi, Roche and Boehringer Ingelheim. 


\section{Author details}

${ }^{1}$ Respiratory Medical Franchise, GSK, Research Triangle Park, NC, USA. ${ }^{2}$ Research Center on Asthma and COPD, University of Ferrara, Ferrara, Italy. ${ }^{3}$ Assistance Publique-Hôpitaux de Paris, Hôpital Bichat, Service de Pneumologie et Centre de Référence des Maladies Pulmonaires Rares, INSERM UMR1152, Paris, France. ${ }^{4}$ Clinical Statistics, GSK, Stockley Park, Uxbridge, UK. ${ }^{5}$ Respiratory Therapeutic Area, GSK, Research Triangle Park, NC, USA. ${ }^{6}$ Respiratory Medical Franchise, GSK, Brentford, Middlesex, UK. ${ }^{7}$ Present address: Avillion US Inc., Northbrook, LL, USA.

Received: 14 May 2019 Accepted: 15 July 2019

Published online: 30 July 2019

\section{References}

1. Global asthma report. http://globalasthmareport.org/. Accessed 16 Oct 2018.

2. Chung KF, Wenzel SE, Brozek JL, Bush A, Castro M, Sterk PJ, Adcock IM, Bateman ED, Bel EH, Bleecker ER, et al. International ERS/ATS guidelines on definition, evaluation and treatment of severe asthma. Eur Respir J. 2014;43:343-73.

3. Wenzel S. Severe asthma: from characteristics to phenotypes to endotypes. Clin Exp Allergy. 2012;42:650-8.

4. Mepolizumab (NUCALA) US prescribing information. https://www. accessdata.fda.gov/drugsatfda_docs/label/2015/1255260rig1s000Lbl.pdf. Accessed 4 Dec 2018.

5. Mepolizumab (NUCALA) EU summary of product characteristics. https:// www.ema.europa.eu/documents/product-information/nucala-epar-productinformation_en.pdf. Accessed 4 Dec 2018.

6. Bel EH, Wenzel SE, Thompson PJ, Prazma CM, Keene ON, Yancey SW, Ortega HG, Pavord ID, SIRIUS Investigators. Oral glucocorticoid-sparing effect of mepolizumab in eosinophilic asthma. N Engl J Med. 2014;371: 1189-97.

7. Chupp GL, Bradford ES, Albers FC, Bratton DJ, Wang-Jairaj J, Nelsen LM, Trevor JL, Magnan A, Ten Brinke A. Efficacy of mepolizumab add-on therapy on health-related quality of life and markers of asthma control in severe eosinophilic asthma (MUSCA): a randomised, double-blind, placebocontrolled, parallel-group, multicentre, phase $3 \mathrm{~b}$ trial. Lancet Respir Med. 2017:5:390-400.

8. Ortega HG, Liu MC, Pavord ID, Brusselle GG, FitzGerald JM, Chetta A, Humbert M, Katz LE, Keene ON, Yancey SW, et al. Mepolizumab treatment in patients with severe eosinophilic asthma. N Engl J Med. 2014;371:1198-207.

9. Hendrikx J, Haanen J, Voest EE, Schellens JHM, Huitema ADR, Beijnen JH. Fixed dosing of monoclonal antibodies in oncology. Oncologist. 2017;22:1212-21.

10. Garcia-Rio F, Alvarez-Puebla MJ, De Esteban I, Barranco P, Olaguibel JM. Obesity and asthma. Key clinical questions. J Investig Allergol Clin Immunol. 2018;29. https://doi.org/10.18176/jiaci.0316.

11. Smit C, De Hoogd S, Bruggemann RJM, Knibbe CAJ. Obesity and drug pharmacology: a review of the influence of obesity on pharmacokinetic and pharmacodynamic parameters. Expert Opin Drug Metab Toxicol. 2018;14:275-85.

12. Jones PW. Interpreting thresholds for a clinically significant change in health status in asthma and COPD. Eur Respir J. 2002;19:398-404.

13. Cloutier MM, Schatz M, Castro M, Clark N, Kelly HW, Mangione-Smith R, Sheller J, Sorkness C, Stoloff S, Gergen P. Asthma outcomes: composite scores of asthma control. J Allergy Clin Immunol. 2012;129:S24-33.

14. GSK Clinical Studies Register. https://www.gsk-studyregister.com/study/6079. Accessed 19 July 2019.

15. Sposato B, Scalese M, Milanese M, Masieri S, Cavaliere C, Latorre M, Scichilone N, Matucci A, Vultaggio A, Ricci A, et al. Factors reducing omalizumab response in severe asthma. Eur J Intern Med. 2018;52:78-85.

16. Trudo F, Hirsch I, Gopalan G, Martin U. Impact of body mass index on efficacy of benralizumab in patients with severe, uncontrolled eosinophilic asthma: pooled analysis of the SIROCCO and CALIMA trials. Am J Respir Crit Care Med. 2018;197:A2490.

17. Pavord ID, Korn S, Howarth P, Bleecker ER, Buhl R, Keene ON, Ortega H, Chanez P. Mepolizumab for severe eosinophilic asthma (DREAM): a multicentre, double-blind, placebo-controlled trial. Lancet. 2012;380:651-9.

18. Haldar P. Patient profiles and clinical utility of mepolizumab in severe eosinophilic asthma. Biologics. 2017;11:81-95.

19. Ortega H, Li H, Suruki R, Albers F, Gordon D, Yancey S. Cluster analysis and characterization of response to mepolizumab. A step closer to personalized medicine for patients with severe asthma. Ann Am Thorac Soc. 2014;11:1011-7.
20. Ortega H, Albers F, Llanos-Ackert J, Bradford E, Price R, Pouliquen I, Castro M. P506. Impact of weight on the efficacy of mepolizumab in patients with severe eosinophilic asthma. Ann Allergy Asthma Immunol. 2017;119:e3-4.

21. Chia YL, Yan L, Yu B, Wang B, Barker P, Goldman M, Roskos L. Relationship between benralizumab exposure and efficacy for patients with severe eosinophilic asthma. Clin Pharmacol Ther. 2019. https://doi.org/10.1002/ cpt.1371.

22. Novosad S, Khan S, Wolfe B, Khan A. Role of obesity in asthma control, the obesity-asthma phenotype. J Allergy (Cairo). 2013;2013:538642.

23. Desai D, Newby C, Symon FA, Haldar P, Shah S, Gupta S, Bafadhel M, Singapuri A, Siddiqui S, Woods J, et al. Elevated sputum interleukin-5 and submucosal eosinophilia in obese individuals with severe asthma. Am J Respir Crit Care Med. 2013;188:657-63.

24. Scott HA, Gibson PG, Garg ML, Wood LG. Airway inflammation is augmented by obesity and fatty acids in asthma. Eur Respir J. 2011;38:594-602.

25. Lugogo N, Green CL, Agada N, Zhang S, Meghdadpour S, Zhou R, Yang S, Anstrom KJ, Israel E, Martin R, et al. Obesity's effect on asthma extends to diagnostic criteria. J Allergy Clin Immunol. 2018;141:1096-104.

26. Dirks NL, Meibohm B. Population pharmacokinetics of therapeutic monoclonal antibodies. Clin Pharmacokinet. 2010;49:633-59.

27. Lowe PJ, Georgiou P, Canvin J. Revision of omalizumab dosing table for dosing every 4 instead of 2 weeks for specific ranges of bodyweight and baseline IgE. Regul Toxicol Pharmacol. 2015;71:68-77.

28. Pouliquen IJ, Kornmann O, Barton SV, Price JA, Ortega HG. Characterization of the relationship between dose and blood eosinophil response following subcutaneous administration of mepolizumab. Int I Clin Pharmacol Ther. 2015:53:1015-27.

29. Reslizumab (CINQAIR) US prescribing information. https://www.accessdata. fda.gov/drugsatfda_docs/label/2016/761033lbl.pdf. Accessed 21 Mar 2019.

\section{Publisher's Note}

Springer Nature remains neutral with regard to jurisdictional claims in published maps and institutional affiliations.
Ready to submit your research? Choose BMC and benefit from:

- fast, convenient online submission

- thorough peer review by experienced researchers in your field

- rapid publication on acceptance

- support for research data, including large and complex data types

- gold Open Access which fosters wider collaboration and increased citations

- maximum visibility for your research: over $100 \mathrm{M}$ website views per year

At BMC, research is always in progress.

Learn more biomedcentral.com/submissions 